\title{
Mercancía humana: mistificación del proletariado y centralidad de la cuestión laboral
}

\section{HUMBERTO MÁRQUEZ COVARRUBIAS*}

La fuerza de trabajo no es una mercancía pero es tratada como si lo fuera. De hecho es la mercancía más importante para el desarrollo del capitalismo, pues es la única capaz de producir plusvalor, la sustancia vital del sistema. El capitalismo tiene como premisa despojar a las clases populares de medios de producción y de sustento para obligarlos a vender su corporalidad y capacidad de trabajo, el trabajo vivo, por un salario, y someterse a los designios patronales que sólo tienen como premisa extraer el máximo beneficio. Tendencialmente, se imponen políticas de constricción salarial, lo cual entra en conflicto con la necesidad de realización del capital, el neoliberalismo impulsa entonces un sometimiento por deudas para hacer posible que consuman los pobres. Producción y reproducción se articulan con la intención de cerrar la pinza de un proletariado desbordante, sin fronteras, cada vez más sometido. En ese sentido, la emancipación humana significa un proyecto utópico, transformador, de cambio social, que reposa en el sueño proletario.

\section{Una palabra proscrita}

Dos características refieren las coordenadas del concepto de clases sociales: a) Es relacional, unas clases se definen con relación a otras, por ejemplo, las trabajadoras frente a las propietarias, de tal suerte que en la moderna sociedad capitalista el burgués vive de la propiedad de los medios de producción y de la explotación de la fuerza de trabajo; en tanto que el proletariado ha sido despojado de medios de producción y subsistencia por lo que se ve compelido a venderle al burgués su fuerza de trabajo para sobrevivir. b) Está en constante transformación en virtud de los cambios en los mecanismos de generación y apropiación de plusvalor donde confluyen formas de movilidad y expansión del capital, políticas estatales y renovadas formas de resistencias de las clases explotadas, por lo cual existe contradicción, conflicto, lucha entre la clases relacionadas.

La ideología burguesa considera que el dominio social de la propia burguesía es legítimo 
por razones de tradición, herencia, riqueza, conocimiento y poder. Pese a que una ínfima minoría de la sociedad pertenece a la clase burguesa, la gran mayoría comparte la ideología dominante, por ello se facilita la servidumbre, el consentimiento de los dominados.

Siempre ha sido aquilatada por las elites gobernantes la tentativa de desaparecer el potencial político del proletariado. En la actualidad, desde la academia, los medios de comunicación y la clase política han proscrito la palabra proletariado, como si no existiera más en un mundo conformista con el devenir del capital global. No obstante, el proletariado tiene una historia inherente al desarrollo del capitalismo hasta nuestros días. El término proletariado habría sido acuñado en periodos previos a la consolidación del capitalismo industrial. Una de las acepciones más antiguas de la palabra proviene del argot jurídico del Imperio romano. La palabra proletarius significa «perteneciente a los hijos» y proviene del latín proles que significa linaje o descendencia, es decir, proletario es el que sólo posee hijos.

Pero es en el capitalismo cuando se aplica con toda precisión a una de las clases sociales fundamentales. ${ }^{1}$ Una peculiaridad del proletariado es que se trata de un sujeto sin objeto, una «subjetividad sin sustancia», esto es, un sujeto despojado de las condiciones de existencia y que por ello carece de objeto para reproducir su vida. ${ }^{2}$ En esas condiciones, el proletario deviene en asalariado porque sólo posee su corporalidad viviente y la de sus descendientes, ni siquiera se reconoce como dueño del suelo donde vive y donde habrá de morir.

La condición «libre» del proletario se manifiesta en tres niveles sucesivos: a) la liberación de los medios de producción mediada por el despojo y la violencia; b) la libertad aparen-

${ }^{1}$ Karl Marx y Friedrich Engels, Manifiesto del partido comunista, México, Siglo XXI, 2017.

${ }^{2}$ Karl Marx, Elementos fundamentales para la crítica de la economía política (Grundrisse) 1857-1858, México, Siglo XXI, 1971. te de vender su fuerza de trabajo al mejor postor, aceptando la servidumbre ante el patrón, si no quiere perecer; c) con la proliferación del mundo de las mercancías, además se suma la libertad de poseer objetos, vía el consumo, que también se traduce en una servidumbre por deudas, dada la insuficiencia del salario. La triple libertad del proletariado no es más que mera servidumbre.

\section{Moderno trabajo esclavo}

Desde la Antigüedad, el trabajador era considerado como «esclavo a tiempo parcial», ${ }^{3}$ pero con el advenimiento de la moderna sociedad capitalista, Marx actualiza los términos para referirse de modo más específico al trabajo asalariado como «moderno trabajo esclavo». ${ }^{4} \mathrm{~A}$ diferencia de la esclavitud del mundo antiguo, donde el sujeto del trabajo se vendía de manera permanente y definitiva, en el capitalismo la venta aparece como si fuese de común acuerdo - los tratadistas liberales arguyen que ninguna esclavitud es de mutuo acuerdo, lo que no parece coincidir con la realidad - ${ }^{5}$ un contrato «libre», sin que medie el látigo flamígero de algún capataz o amo. Entonces se presenta una esclavitud perfeccionada, inserta en la sociedad moderna capitalista a grado tal que el esclavo moderno ya no sabe que lo es.

Más allá de la ilusión de que el esclavismo ha sido abolido - aunque se reconoce que fue uno de los puntales del despliegue inicial del capitalismo en las colonias - para dar paso a una sociedad de hombres libres dentro de un mercado libre donde los agentes concurren por voluntad propia, en el capitalismo tardío aún persiste en forma relativa, sutil; pero el salario mistifica la dominación sobre el proletariado al

\footnotetext{
${ }^{3}$ Aristóteles, Política, Madrid, Gredos, 1999, p. 84.

${ }^{4}$ Karl Marx, El capital. Crítica de la economía política, tomo I, vol. 1, México, Siglo XXI, 1988.

${ }^{5}$ John Locke, El ensayo sobre el gobierno civil, México, Porrúa, 2005.
} 
presentarla como una relación de «libertad», cuando el proletariado continúa encadenado a una «nueva forma de esclavitud».

En la medida en que el sujeto sometido a una relación salarial no puede eludir la necesidad de venderse para sobrevivir se encuentra supeditado a una esclavitud relativa. Al acudir al mercado por voluntad propia con objeto de venderse cree que en ese acto busca trabajo sin ser consciente de que él es la personificación del trabajo. ${ }^{6}$ La venta es un acto temporal que dura 8, 10 o 12 horas al día, incluso más; pero también menos, cuatro o cinco horas, y esto último puede considerarse una desgracia. Por tanto es una venta relativa. En determinadas circunstancias puede elegir a qué patrón habrá de venderse; sin embargo, lo que en definitiva no puede elegir es no hacerlo, no venderse, pues la vida se le esfuma. Para el proletariado, la libertad de elección significa la posibilidad de reactualizar la condición de dependencia como sujeto vivo sin objeto.

\footnotetext{
${ }^{6}$ Enrique Dussel, 16 tesis de economía politica. Interpreta-
} ción filosófica, México, Siglo XXI, 2014.

\section{Mercantificación del cuerpo}

En la irracionalidad de la moderna sociedad capitalista, los seres humanos son tratados como si fuesen mercancías, sin serlo y bajo el predominio de la forma salario, los sujetos terminan por ser cosificados. Devienen una especie de cosa a merced de los caprichos del mercado, puesta a la deriva, donde campean las abstractas leyes de la oferta y la demanda, que actúan como si fuesen leyes objetivas e implacables, pautas normativas de la socialidad burguesa. La vida humana es subsumida por la forma salario y tasada por un precio, en términos formales y reales. Entonces, como lo advirtiera Marx, el sujeto es animalizado, reducido a una simple humanité.

El proletario se convierte en asalariado porque está obligado a vender su fuerza de trabajo para sobrevivir, a ofrecerse y cosificarse como una mercancía más en el mercado laboral. Pero es una falsa mercancía, pues nadie produce

${ }^{7}$ Karl Marx, Manuscritos económicos y filosóficos de 1844, Buenos Aires, Colihue, 2006.
Desde la Antigüedad el trabajador era considerado como «esclavo a tiempo parcial», pero con el advenimiento de la moderna sociedad capitalista, Marx actualiza los términos para referirse al trabajo asalariado como «moderno trabajo esclavo».

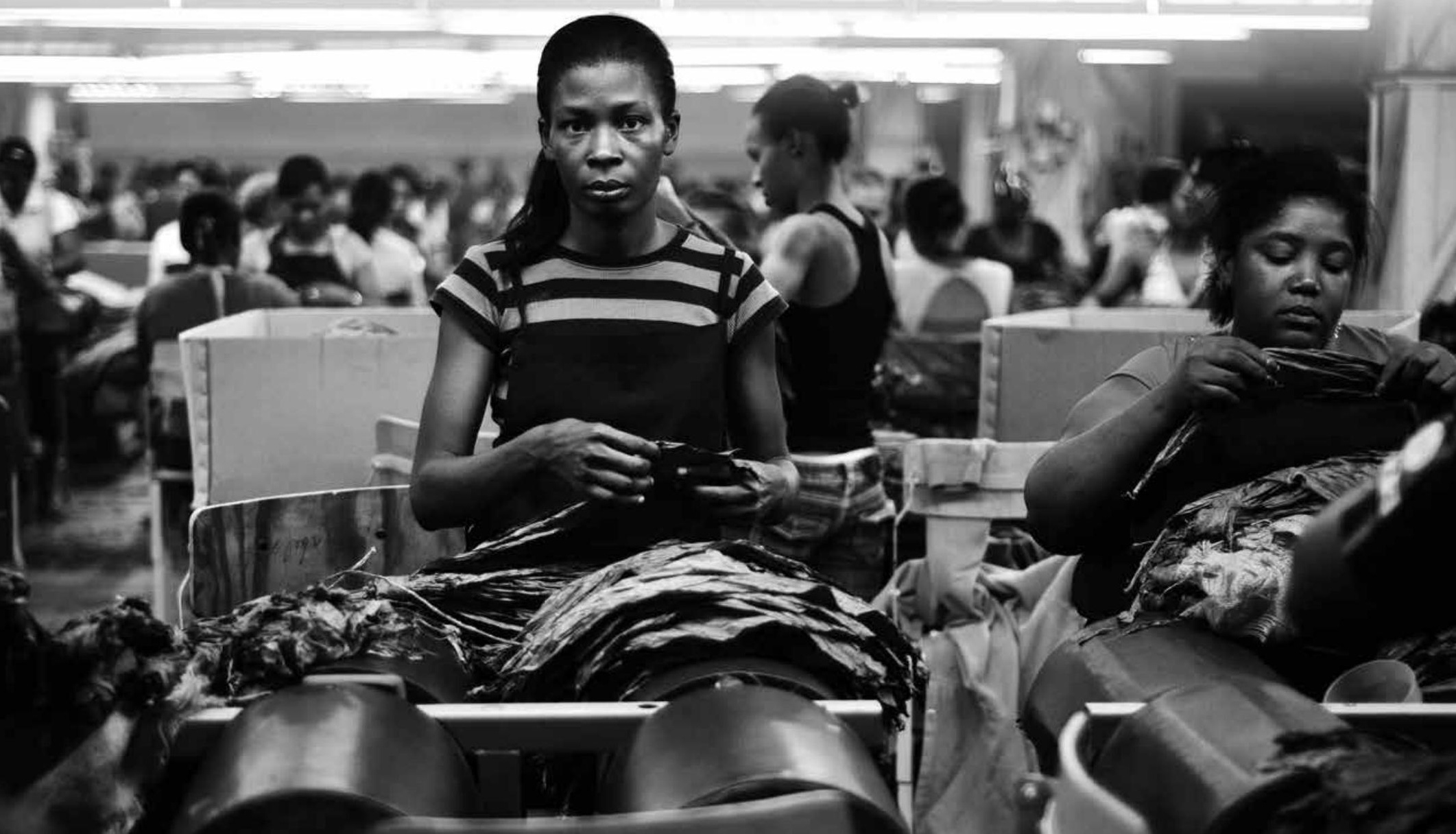


fuerza de trabajo para venderla, inserta en un mercado laboral que técnicamente no existe.

Al vender su fuerza de trabajo el sujeto está mercantificando su cuerpo y sus capacidades individuales. La fuerza de trabajo que porta consigo el proletariado, su única posesión real que ofrenda al mercado, no es abstracta sino concreta, está adherida a la corporalidad viviente. Pero no vende su trabajo, que es consustancial al cuerpo, sino que vende la fuerza de trabajo, es decir, la capacidad de desplegar una actividad praxiológica dentro de un modo sociotécnico de producción, por esa razón no puede ofrecerla en el mercado sin también ofrecerse él mismo. Es un acto ajeno a su propia voluntad. En síntesis: cuando el sujeto acude al mercado para vender su fuerza de trabajo significa que va a venderse a sí mismo, así sea de forma relativa, como «esclavo a tiempo parcial».

\section{Posmodernismo desbocado}

Desde distintas opciones ideológicas, el concepto axial de clases sociales ha sido objetado bajo la idea de que la clase trabajadora, si acaso habría existido, se ha difuminado una vez que se ha desmoronado la base constitutiva industrial y la pulsión de la productividad fordista. ${ }^{8}$

La sentencia de que el proletariado industrial había dejado de existir o estaba en vías de extinción es convalidada desde diferentes posiciones e intencionalidades políticas. ${ }^{9}$ A este veredicto se han sumado filósofos procedentes de diversas posturas del espectro político, desde los críticos izquierdistas de la ortodoxia marxista, ${ }^{10}$ pasan-

\footnotetext{
${ }^{8}$ Zygmunt Bauman, Modernidad líquida, México, Fondo de Cultura Económica, 2004; Ulrich Beck, La sociedad del riesgo. Hacia una nueva modernidad, Barcelona, Paidós, 1998; Richard Sennett, La cultura del nuevo capitalismo, Barcelona, Anagrama, 2006.

${ }^{9}$ Enrique de la Garza, Hacia un concepto ampliado del trabajo. Del concepto clásico al no clásico, México, Anthropos, 2010.

${ }^{10}$ André Gorz, Adiós al proletariado. Más allá del socialismo, Barcelona, El Viejo Topo, 1981; Antonio Negri y Michael Hardt, Imperio, Buenos Aires, Paidós, 2002; John Holloway,
}

do por exmarxistas y posmodernos conversos, ${ }^{11}$ hasta los teóricos conservadores de la derecha. ${ }^{12}$

El punto de inflexión fue el advenimiento de la «sociedad postindustrial» derivada de la superación del modelo de producción fordista propio de la producción industrial en línea y el consecuente cambio estructural en la sociedad moderna..$^{13}$ Entonces se decreta el término del paradigma productivo, que denotaba la extinción del marxismo, y a cuyo mentor se le atribuía una suerte de idolatría por la producción, para suplirlo con el paradigma de la comunicación. La cuestión del trabajo cae en el olvido y se entroniza el análisis del discurso. ${ }^{14}$

En dicho veredicto, el proletariado se habría reducido a su mínima expresión y confinado en los reductos de las supervivientes fábricas comparado a una desbordante masa de trabajadores ocupados en los servicios donde no se reconocen como proletarios, sino como «clases medias», pues el salario se metamorfosea en un simple ingreso y se entregan a las proclamas seductoras de la «sociedad de consumo». Con la «desmaterialización de la economía», la sociedad se basa en los «servicios» y el proletariado industrial ya no tiene cabida.

\section{Relativismo cultural}

Con el advenimiento de la sociedad del conocimiento y la sociedad del consumo, ya no la

Cambiar el mundo sin tomar el poder. El significado de la revolución hoy, Buenos Aires, Herramienta Ediciones/Universidad Autónoma de Puebla, 2002.

${ }^{11}$ Jean Baudrillard, La sociedad de consumo. Sus mitos, sus estructuras, Madrid, Siglo XxI, 2009; Jean-François Lyotard, La condición posmoderna. Informe sobre el saber, Madrid, Cátedra, 1987; Cornelius Castoriadis, La institución imaginaria de la sociedad, Buenos Aires, Tusquets, 2010; Agnes Heller, Políticas de la posmodernidad, Barcelona, Península, 1989.

${ }^{12}$ Daniel Bell, El advenimiento de la sociedad post-industrial: un intento de prognosis social, Madrid, Alianza, 1976; Francis Fukuyama, El fin de la historia y el último hombre, Madrid, Alianza, 2015.

${ }^{13}$ Daniel Bell, op. cit.

${ }^{14}$ Jürgen Habermas, Teoría de la acción comunicativa, Madrid, Taurus, 1981. 
sociedad mercantil ni la sociedad de la explotación, se arribaba al «fin de las ideologías», ${ }^{15}$ el «fin de las grandes narrativas» ${ }^{16}$ y el «fin de la historia». ${ }^{17}$ Algunos autores que otrora cuestionaban acerbamente al capitalismo ahora proponen nociones imprecisas, como la «multitud», ${ }^{18}$ que pretenden ejercer un papel sustituto de categorías con mayor potencial crítico.

El ambiente posmoderno desbocado reniega de las clases sociales y sus luchas de transformación social, para entronizar el relativismo cultural que concede mayor reconocimiento a la diversidad de las singularidades y reivindica las identidades, diferencias y especificidades culturales. Con el dictamen sumario acerca de la supuesta pérdida de centralidad de la clase trabajadora, en el capitalismo tardío se adujo que no había más clase obrera sino en todo caso una suerte de «no clase de los no trabajadores», lo cual en definitiva implicaba decir «adiós al proletariado». ${ }^{19}$ Fin de la historia.

En ese sentido, el profuso relativismo cultural deniega las clases trabajadoras explotadas y en su lugar se solaza desmenuzando a una masa informe de conjuntos humanos, la «multitud», en variopintas representaciones fragmentarias, según referentes étnicos (mayas, quichés, aymaras, afros, mapuches, mijes, tojolabales), preferencias sexuales (lesbianas, transexuales, heterosexuales, bisexuales, homosexuales), condición de género (mujeres, madres solteras), tribus urbanas (cholos, emos, punks, sanjuditas, urbanitas, chairos), grupos lingüísticos (latinos, mixes, huicholes), grupos etarios (niños, jóvenes, adultos mayores, ninis, millennials), marginados (vagabundos, criminales, locos), bohemios (artistas, músicos, poetas), entre otros. A lo sumo, la que era sociedad de clases se reduce a una mezcla social de identidades fragmentarias.

\footnotetext{
${ }^{15}$ Daniel Bell, El fin de las ideologías, Madrid, Tecnos, 1964.

${ }^{16}$ Jean-François Lyotard, op. cit.

${ }^{17}$ Francis, Fukuyama, op. cit.

${ }^{18}$ Antonio Negri y Michael Hardt, op. cit.

${ }^{19}$ André Gorz, op. cit.
}

Con la exaltación de los estudios culturales posmodernos se pretende borrar la crítica de la economía política y resaltar como rasgos distintivos de la sociedad la diversidad de lenguas, las identidades, las diferencias de género y los orígenes étnicos, el hecho de que algunos segmentos estén inmersos en actividades productivas o excluidos de ellas se considera un aspecto secundario o irrelevante. En descargo de una clase obrera homogénea, en la actualidad existe — quizá siempre lo ha habido — una masa de singularidades irreductible al «esquema reduccionista» del proletariado.

\section{Estereotipos de clase}

Las principales clases sociales antagónicas de la sociedad moderna, la burguesía y el proletariado, a menudo suelen ser caricaturizadas por los caricaturistas de la prensa y la opinión pública. En la cúspide de la pirámide social, la burguesía suele ser dibujada con un cuerpo adiposo en forma de cerdo que asoma la cola enroscada, ataviado con traje de frac negro, sombrero de bombín, ostentando joyas y billetes desbordantes, puro en la mano y una copa de whisky o coñac en la otra.

El proletariado también ha sido caricaturizado. En ocasiones se le rinde pleitesía cuando el obrero aparece representado con un cuerpo robusto forjado por la extenuante jornada laboral, enfundado en su overol, botas y casco, impregnado de aceite y sudor, que contempla el horizonte con mirada adusta. Además, la ondeante bandera roja comunista retoma las herramientas de trabajo, la hoz y el martillo para simbolizar la unción entre obreros y campesinos. Aunque de igual modo se elaboran caricaturas de un personaje famélico, pedigüeño, menesteroso, que lleva a cuestas el peso de la vida y arrastra su pobreza.

Ahora, las revistas frívolas, llamadas del corazón, vindican cínicamente la riqueza, que antes se ocultaba, y la muestran con descaro en 
señal de triunfo, como la viva imagen del éxito. La revista Forbes publica cada año la lista de los que considera los hombres más ricos del mundo. En contraste, los movimientos de indignados han popularizado la fórmula del 1 por ciento para referirse a los más ricos del mundo, una plutocracia acerba que no tiene límites.

Además de la disolución teórica del proletariado a manos de posmodernos y neoliberales que niegan su existencia, los medios de comunicación, en realidad de condicionamiento de masas, se ocupan febrilmente de estigmatizar al proletariado realmente existente. Las industrias culturales dominadas por las oligarquías utilizan sus canales de entretenimiento e información, sustentados en programación pueril, para denostar la imagen pública del proletariado, a la vez que rinden pleitesía a la ostentación de riqueza de los potentados. El proletariado se encuentra actualmente «demonizado». ${ }^{20}$ La pobreza de los proletarios es vapuleada y los jóvenes pobres reciben toda suerte de epítetos: chaus, cañis, chuntaros, prole. A su vez, los burócratas y empleados de empresas públicas y privadas son señalados como los godínez, personajes hundidos en la más completa mediocridad, cuya cotidianidad gira en torno a los ciclos quincenales.

\section{Clasemediero}

La ideología de la «clase media» ha permeado con fuerza, según la cual el nivel de ingresos — no el salario - y los estudios universitarios son los factores que ubican a una gran franja de la población en un estatus social preferente dentro de la sociedad de consumo o la sociedad del conocimiento, un estatus diferente al de los simples obreros, que ocupan los peldaños inferiores al recibir bajos ingresos y no disponer de preparación académica relevante.

${ }^{20}$ Owen Jones, Chavs. La demonización de la clase obrera, Madrid, Capitán Swing, 2013.
Por lo visto, los esclavos modernos no se asumen como tales, de hecho se mofan de otros a quienes estigmatizan como «prole». No se consideran, en modo alguno, explotados; eso parecería ser cosa del pasado. Para justificarse anteponen su nivel educativo, el título académico, la profesión y el hecho de no trabajar en una fábrica sino, por ejemplo, en una oficina; además de poseer casa (pagada con un oneroso crédito hipotecario por el resto de la vida); disponer de automóvil (pagado a meses sin intereses); contar con servicio de internet y televisión por cable en casa y usar continuamente artefactos digitales como el teléfono celular; amén de asumir hábitos consumistas como ir de shopping a los centros comerciales e ir al cine, viajar como turistas en días de «puente» o en vacaciones; incluso vestir de traje y corbata, no usar más que ropa de «marca» o ser fashion. ${ }^{21}$

En la denominada «sociedad del conocimiento» las apariencias engañan, de tal suerte que quienes se presentan ataviados con traje y corbata — no con overol industrial—, no estarían sujetos a la explotación laboral; si acaso venden algo es su conocimiento y cobran según su formación educativa, no valen por lo que hacen — como los trabajadores manuales - sino por lo que saben.

Esta ideología se encuentra plagada de prejuicios, por una parte rechazan la pertenencia a una clase social, la de los explotados, y desprecian a quienes consideran inferiores, los trabajadores; y por otra parte anhelan ascender a las esferas de las elites potentadas, a quienes en cambio idolatran.

\section{Desposesión}

Más allá de la multitud de singularidades que derivaría en la presunta disolución del proletariado, como sostiene el posmodernismo

${ }^{21}$ Alejando González, «El silencio de los proletarios. La mistificación del salario y la esclavitud capitalista», Memoria, núm. 256, 2015. 
desbocado, la cuestión de fondo es el modo en que viven los sujetos, la forma en que acceden a las condiciones materiales necesarias para subsistir y reactualizar su singularidad desde donde brota la pluralidad. El problema entonces es dilucidar si estos individuos singulares, los conjuntos familiares, las comunidades y los pueblos acaso son dueños o no de los medios de producción que posibilitan la reproducción material y espiritual de los individuos y las colectividades.

Con lo anterior no se pretende afirmar que está en cuestión la propiedad privada en general, como plantearía el «comunismo tosco», que con la pretendida abolición de la propiedad privada y la comunitarización de todo estaría generalizando la propiedad colectiva y pervirtiendo las relaciones sociales. ${ }^{22}$ El punto crítico es la propiedad privada de los medios de producción, por ejemplo una empresa privada que garantiza el acceso a la riqueza social de manera plena y permanente, a quienes forman parte de la elite que detenta la riqueza, o si por lo contrario tienen que verse compelidos a venderse en el mercado

\footnotetext{
${ }^{22}$ Adolfo Sánchez Vázquez, El joven Marx. Los manuscritos
} de 1844, México, Ítaca, 2003. laboral por un salario, con el que «compran cosas», en el sacrosanto mercado, que les permitirán sobrevivir por un lapso breve, por ejemplo la próxima quincena.

El proletariado es una subjetividad sin sustancia, un sujeto sin objeto, por tanto es una gran masa de desposeídos, un sujeto colectivo separado, escindido, de su objeto social, que se ve obligado a vender su fuerza de trabajo a cambio de un salario para obtener aquello que la cultura moderna los instiga a adquirir compulsivamente. ${ }^{23}$

La condición de trabajador asalariado deviene de ser proletario. En tanto que para ser asalariado previamente hay que ser proletario, lo opuesto no sucede. Existen proletarios no asalariados, dado que no han accedido a un empleo donde recibir un salario, por lo cual forman el «ejército industrial de reserva», según Marx, ${ }^{24}$ aunque los economistas convencionales se referirán a ellos como desempleados, sin soslayar que puede tratarse de personas que no venden su fuerza de trabajo por razones de edad o incapacidad.

${ }^{23}$ Slavoj Zizek, Permanencia de lo negativo, Buenos Aires, Ediciones Godot, 2016.

${ }^{24}$ Karl Marx, El capital...

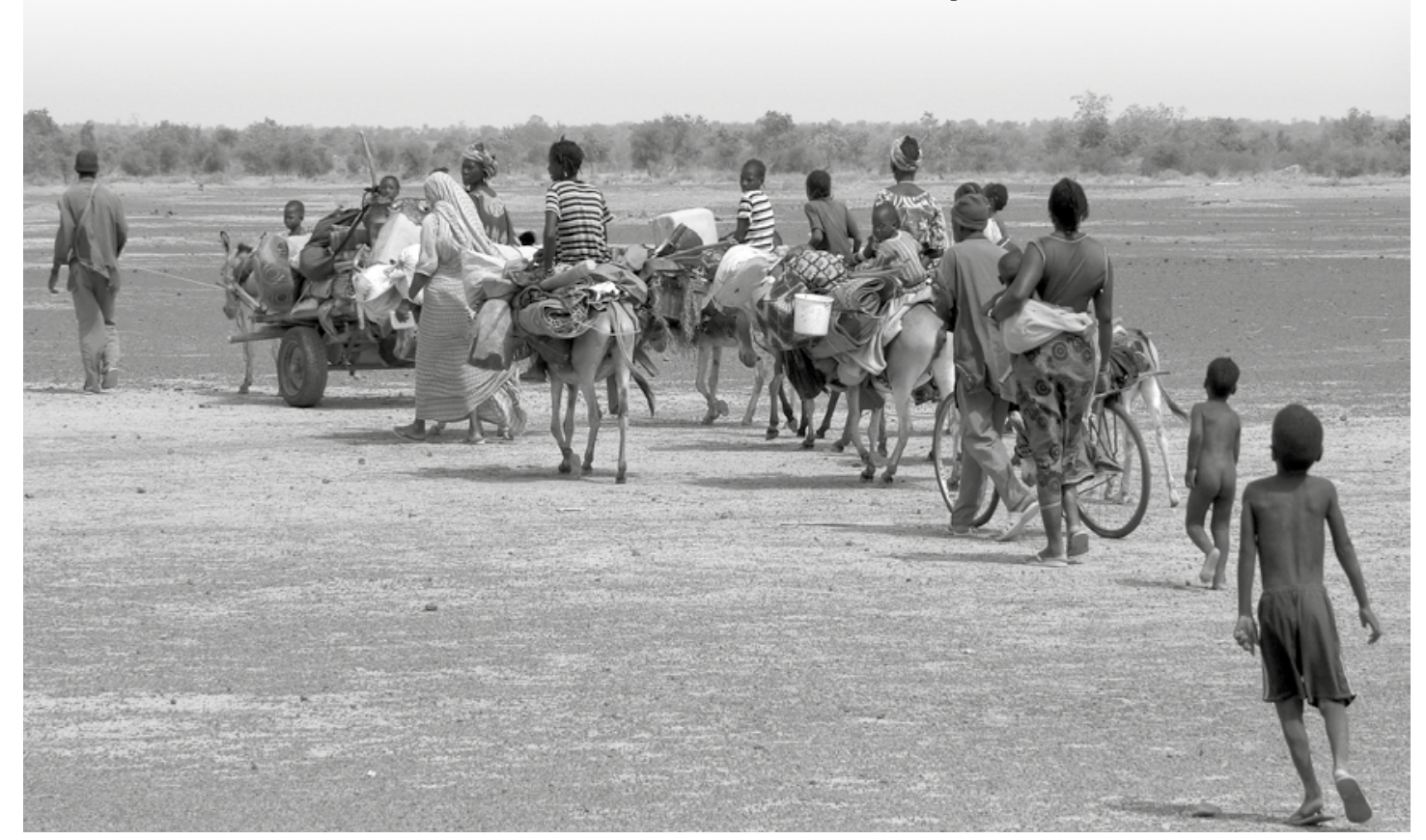

El proletariado es una subjetividad sin sustancia, un sujeto sin objeto, por tanto es una gran masa de desposeídos, un sujeto colectivo separado, escindido, de su objeto social, que se ve obligado a vender su fuerza de trabajo a cambio de un salario para obtener las cosas que la cultura moderna le impele a adquirir compulsivamente. 
Entonces, para ser asalariado, previamente hay que ser proletario. La condición de proletario deviene de ser desposeído, estar despojado del objeto, y se convierte en asalariado porque se le coacciona a vender su fuerza de trabajo a cambio de un salario que a la postre le posibilitará obtener las cosas, las mercancías, que le permitirán sobrevivir y sentirse parte del mundo de las mercancías. En todo caso, el proletario es un sujeto despojado que no posee los objetos para producir las condiciones materiales, objetivas y subjetivas, para reproducir su vida en forma autónoma y permanente, de ahí que se torne un sujeto despojado, pobre y necesitado.

\section{Alienación}

Para el capitalismo, no sólo es crucial la producción, lo es también la reproducción, razón por la cual al despojo y explotación se suma el consumo y la ideología. La explotación productiva del trabajador, esto es, que se extraiga determinada dosis de plusvalor al trabajo vivo, no lo convierte de por sí en proletario o asalariado sino que previamente es necesario que haya sido desprovisto de medios propios de producción y subsistencia, para proletarizarlos. En adición, una vez inmerso en el mercado laboral tendrá que continuar ofrendando su tiempo y hábitos a fin de hacer posible la reproducción del sistema mediante el consumo, la cultura y la ideología.

En el capitalismo contemporáneo la fuerza de trabajo, el valor de uso de los asalariados, se consume de las más diversas e inauditas formas en tanto se transforman las actividades de la producción y la circulación: la producción industrial es mejorada técnicamente con la automatización y la robotización, además de la división internacional del trabajo y la deslocalización (maquiladoras, minería, agronegocios); los servicios se expanden en bancos, tiendas de conveniencia, cafeterías, restaurantes, hoteles, gastronomía, aviación, call center, docencia, policía, militar, etcétera.

Durante la jornada laboral, el trabajador no es dueño de su tiempo, le pertenece al capitalista. No puede hacer lo que le plazca, pues ha vendido su tiempo, energía y corporalidad, y está obligado a obedecer las órdenes de aquel que al ostentar el poder del dinero lo ha comprado temporalmente. Aunque la jerga convencional dirá que lo ha «contratado» o, mejor aún, «empleado».

Después de ser explotado, de que la fuerza de trabajo sea usada para crear plusvalor, incluso en grado superlativo, es decir, superexplotado, ${ }^{25}$ se aviene el problema de ser subsumido en las formas de reproducción social, donde interviene la esfera del consumo, la cultura, la ideología y la vida cotidiana. ${ }^{26}$

Apenas concluya ese tiempo, el trabajador podrá experimentar la sensación de ser dueño de sí mismo de nueva cuenta, aunque sólo sea para reponerse del desgaste sufrido durante la jornada laboral para estar en condiciones de ser despellejado, exprimido, cuando el nuevo día le anuncie su verdadera condición.

Habitualmente, durante el «tiempo libre» el trabajador dedicará considerables bloques de tiempo simplemente para trasladarse de su casa al lugar de trabajo, salvo que ese lugar sea su mismo hogar, y otro tanto para el descanso, sin embargo en esos periodos no podrá escapar a la lógica del capital, estará subsumido a ella como consumidor. ${ }^{27}$ La ecuación se complementa con la igualdad entre descanso y consumo, entre tiempo libre y tiempo de comprar. Incluso el propio acto de comprar es delegado al comprador, quien tiene que invertir parte de su tiempo

${ }^{25}$ Ruy Mauro Marini, Dialéctica de la dependencia, México, Era, 1973.

${ }^{26}$ Humberto Márquez Covarrubias, «Apogeo del capitalismo corporativo y dominación de los mundos de vida», Estudios Críticos del Desarrollo, vol. 3, núm. 5, 2014.

${ }^{27}$ Robert Kurz, «La expropiación del tiempo», La Haine, 27 de diciembre de 2012, https://www.lahaine.org/est_espanol. php/la-expropiacion-del-tiempo; Renán Vega, «La expropiación del tiempo en el capitalismo actual», Herramienta, núm. 51, 2012. 
para hacer sus compras, en descargo de empleados despedidos. De modo que la subsunción del trabajo por el capital se complementa con la subsunción del consumo y de las actividades de reproducción social en general.

\section{Entretelones salariales}

En la economía mundial, el desarrollo desigual y las relaciones de poder entre Estados nacionales interfieren en la prevalencia de grandes diferenciales salariales que segrega a vastas regiones del mundo y, en particular, a las clases trabajadoras. Pero la existencia de los diferenciales salariales no altera el fundamento de la condición proletaria en el seno de una sociedad mercantil. En el mundo del trabajo la existencia de diversos niveles salariales no disuelve el asunto, pero mistifica la conciencia de clase, pues se asume que el mercado gratifica de manera diferenciada el «precio de la fuerza de trabajo» según su preparación, calificación o prestigio.

Más bien prevalece una desproporcionalidad en la distribución social del valor que se verifica por una desigualdad notoria entre el esfuerzo laboral y su retribución; por ejemplo, entre quien se vende a 2 mil pesos o más por una hora y quien se vende a 7.30 pesos o menos por hora. En la práctica, algunos se llevan mucho más de lo que aportan: la elite de la clase política, los futbolistas encumbrados, los cantantes de moda o los gerentes de grandes empresas se embolsan cantidades estratosféricas. En contraste, los jornaleros agrícolas, los operarios de maquiladoras o los despachadores de tiendas de conveniencia reciben míseros salarios de hambre.

Entonces, la cuestión de fondo no puede solucionarse con el alza de los salarios nominales, incluso un incremento que compensara la inflación anual de los precios de la canasta básica o uno mayor que pretenda revertir la pérdida acumulada del poder adquisitivo. Aun así, ba- jo el capitalismo, y más dentro de su caparazón neoliberal, estas medidas compensatorias no son concesiones de los organismos patronales ni los gobiernos de turno, si acaso pudieran lograrse sería merced a la lucha organizada de los trabajadores mediante sindicatos, movimientos sociales y partidos políticos afines a los intereses populares (en todo caso esa política no resuelve el problema de raíz).

La lucha sindical desplegada en huelgas, paros o marchas reivindica mejores condiciones de trabajo, en particular el salario y las prestaciones; no obstante, son estrategias de lucha que a la postre concitan formas de inclusión dentro de la trama de la explotación en condiciones quizá algo menos oprobiosas, para lo cual tendrán que entablar negociaciones con el Estado y los patrones sin pretender abolir las relaciones de dominación y explotación subyacentes.

Paradójicamente, en la moderna sociedad capitalista existe algo peor que ser un trabajador mal pagado: no serlo, estar «desempleado». $\mathrm{Pa}-$ ra la mayoría de los asalariados, «tener un trabajo» donde ser explotados, a expensas de cómo lo hagan, resulta una suerte de «bendición», por lo que en lugar de cuestionar la situación, más valdría «dar las gracias al Señor». En contraste, otros segmentos laborales manifiestan regocijo por estar insertos en el sistema de explotación en virtud de que su precio de asalariado está por encima del promedio y se identifican como parte de la «clase media alta», recreando el llamado «proletariado burgués» ${ }^{28}$ o la «aristocracia obrera», ${ }^{29}$ la cual se encuentra en vías de extinción en el capitalismo neoliberal. En el primer caso la consigna de los desempleados parecería ser «iqueremos ser explotados!»; la de los asalariados, «iqueremos ser un poco menos explotados!»; y la de los clasemedieros resulta patética porque rememoran a ciertos esclavos negros

${ }^{28}$ Friedrich Engels, «Carta de Engels a Marx del 7 de octubre de 1858», Correspondencia, Buenos Aires, Cártago, 1987.

${ }^{29}$ Vladimir Lenin, Imperialismo. Fase superior del capitalismo, México, Quinto Sol, 2009. 
La burguesía suele ser dibujada con un cuerpo adiposo en forma de cerdo que asoma la cola enroscada, ataviado con traje de frac negro, sombrero

de bombín,

ostentando

joyas y billetes desbordantes, puro en la mano y una

copa de whisky o coñac en la otra. orgullosos porque su amo pagó por ellos un precio más alto que por los demás.

La diferenciación salarial propicia divisiones dentro del proletariado y redunda en luchas intestinas acicateadas por la competencia capitalista y el ethos realista. ${ }^{30}$ Quienes se consideran «mejor pagados» (explotados) consideran como sus principales enemigos a los «peor pagados» (superexplotados), pero ambos segmentos consideran como sus adversarios a los desempleados (ejército industrial de reserva) que simplemente no han podido realizar su fuerza de trabajo como mercancía, como capital variable, en el sentido de Marx, bajo el yugo de ningún capitalista, ni siquiera pueden ser asalariados.

Un ejemplo preclaro de la mistificación es el salario de los migrantes conver-

${ }^{30}$ Bolívar Echeverría, Modernidad, mestizaje cultural, ethos barroco, México, Universidad Nacional Autónoma de México, 1994.
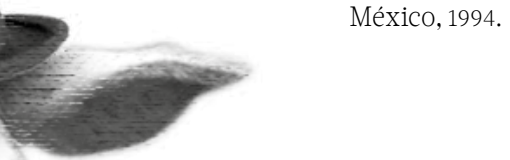

3
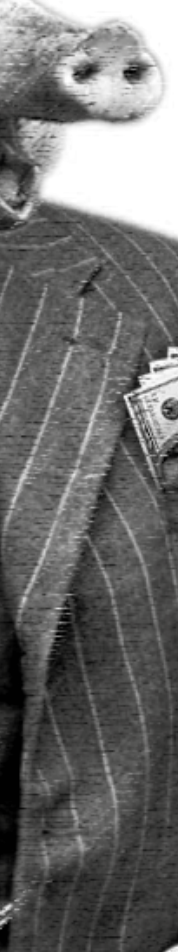
asimétrico, que genera la falsa ilusión de un salario excedente, cuando en realidad se trata

\section{El patrimonio de los desposeídos}

Contra todo pronóstico, en la moderna sociedad capitalista la noción de desposesión que define la condición violenta de separación de os medios de existencia y el hurto sobre los trabajadores en la producción, descritos por Marx como acumulación originaria y explotación, ${ }^{32}$ se pone a prueba en la moderna sociedad capitalista cuando grandes segmentos de proletarios y de asalariados precarizados son insertados a la dinámica del capitalismo do en la «servidumbre por deudas», de forma que consiguen tres grandes objetivos: a) la «inclusión de los excluidos», b) la activación de la demanda efectiva de consumidores de bajos ingresos, c) la aparente disolvencia de a desposesión mediante la posesión de cosas.

El sistema de consumo capitalista incentiva la posesión desmesurada de cosas que satisfacen necesidades básicas y suntuarias. El cos, forma parte de la ideología dominante y de la mistificación de la desposesión, porque entonces parecería que se vive en la abundancia. Dentro del imaginario posesivo el estatus social se define no por el trabajo sino según las cosas que se poseen. De modo que más que para sobrevivir o para que las cosas permitan vivir, pareciera que los proletarios consumistas viven para tener más y más cosas, conforme al llamado del american way of life.

\footnotetext{
${ }^{31}$ Humberto Márquez Covarrubias, «México en vilo: desmantelamiento de la soberanía laboral y dependencia de las remesas», Papeles de población, vol. 14, núm. 58, 2008. ${ }^{32}$ Karl Marx, El capital...
} 
Para su desgracia, más allá de los bienes ostentosos que pudieran llegar a formar su patrimonio, el proletario asalariado continúa siendo una subjetividad sin sustancia, un sujeto sin objeto, en una palabra, un ser desposeído y separado de las condiciones materiales de existencia que le permitan producir de forma autónoma y continuada el cúmulo de cosas que adquiere en el mercado, así como vivir e insertarse en la esfera de la cultura mercantil.

Atrás de la aparente prosperidad de las familias que acumulan cosas, gran parte de esas posesiones pudieran resultar superfluas; en todo caso son adquiridas compulsivamente bajo la pulsión del fetichismo de la mercancía que estimula el consumismo mediado por la mercadotecnia por encima de las necesidades y más allá de las capacidades.

\section{Inclusión social por el consumo}

Con la intención de rescatar a la sociedad mercantil capitalista, empantanada por la insolvencia de los trabajadores mal pagados y la mayoría de la población pobre - que no puede erigir una demanda efectiva y se encuentra inmersa en una crisis de realización - el neoliberalismo engendró una estrategia, ni siquiera imaginada por el keynesianismo, para abrir canales de inclusión a los excluidos mediante la inyección de créditos onerosos para el consumo. Con ello se reactivaría la alicaída demanda y se lograría el doble efecto de activar a la «sociedad de consumo» y generar el espejismo de inclusión en una sociedad que sin embargo mantiene una férrea política de comprensión de los «salarios reales» y la derogación de los derechos sociales y laborales ganados por luchas sociales pretéritas.

Como efecto compensatorio del prolongado deterioro del «salario real», es decir, el descenso progresivo de la capacidad de compra de satisfactores, amén de ser explotada, la población trabajadora es sometida a un régimen de «ser- vidumbre por deuda»; esto es, un consumo a crédito que tendrá entre otras expresiones la sujeción a leyes hipotecarias injustas para subvenir costes de vivienda disparatados — casas paupérrimas a precios de oro- $\mathrm{y}$ en este movimiento quedará bajo la férula de acreedores, gestores de dinero y banqueros privados nacionales y extranjeros.

La inclusión en la sociedad de consumo mistifica el régimen de explotación y la forma salario debido a que el conjunto de bienes que se adquieren por el crédito van conformando el patrimonio de los trabajadores que diluyen la sensación de desposesión, incentivan el estímulo propietario, pero los atrapa en sutiles redes de sujeción crediticia a perpetuidad. Accederán a una vivienda que por más modesta que sea deberán pagar durante el resto de sus días, con el riesgo de que al terminar de pagarla, si no es que antes, se habrá derrumbado; adquirirán un vehículo de corta vida útil para embotellarse en el tráfago de la vialidad urbana; la compra de teléfonos celulares crea la sensación de integración a la tecnología y la formación de «redes sociales» digitales; una plétora de aparatos electrónicos (televisores, computadoras), servicios (internet, televisión de paga) y la expectativa de viajar y gozar de entretenimientos diversos, además los bienes básicos como vestido, calzado, se adquirirán a crédito.

La vía del consumismo abierta mediante la «servidumbre por deudas» significa otra forma encubierta de dominación dentro de la forma de esclavitud moderna. En términos macroeconómicos es una salida para la realización mercantil mediante la demanda efectiva artificial en condiciones de desplome del salario general, a la vez que simula que la vía de inclusión social es consumir más.

\section{Expansión del proletariado}

En desmedro de la tesis que promulga apresuradamente la desaparición del proletariado con 
la culminación del fordismo, el derrumbe del «socialismo real» y el advenimiento de una «sociedad posindustrial», la economía mundial capitalista, lejos de decirle adiós, despliega una expansión sin precedentes del proletariado sobre el conjunto de la humanidad y en todos los confines de la economía mundial. ${ }^{33}$

La mayor parte de la población mundial en el capitalismo contemporáneo es asalariada y, más aún, proletaria. En otras palabras, tiene la necesidad de acudir al mercado laboral y vender su fuerza de trabajo por un salario, con el cual podrá adquirir medios de vida en el mercado para sobrevivir por unos días, al menos para sobrellevarla hasta el siguiente pago quincenal. A sabiendas de que el capitalismo es indiscutiblemente el orden social dominante y generalizado despliega diversas formas de explotación que capturan a los trabajadores no asalariados, que al final de cuentas adquieren medios de producción y consumo en los mercados normalizados por la lógica inmanente del capital. ${ }^{34}$

\section{Sin fronteras}

En la medida en que el capital global rompe las fronteras de los Estados nación se configura un proletariado mundial a su disposición, que todavía tiene restricciones para la libre movilidad y observa grandes diferenciales salariales. ${ }^{35}$ Esto lo aprovecha a plenitud el capital bajo las formas de extractivismo, maquiladora, agroexportación, que se desplaza hacia los grandes reservorios de trabajo barato donde no encuentra mayores restricciones para una li-

\footnotetext{
${ }^{33}$ Michel Husson, «La formación de una clase obrera mundial», A Través del Espejo, núm. 1, 2015.

${ }^{34}$ Armando Bartra, Hacia un marxismo mundano. La clave está en los bordes, México, Ítaca, 2016.

${ }^{35}$ Humberto Márquez Covarrubias y Raúl Delgado Wise, «Signos vitales del capitalismo neoliberal: imperialismo, crisis y transformación social», Estudios Críticos del Desarrollo, vol. 1, núm. 1, 2011; Raúl Delgado Wise y David Martin, «La economía política del arbitraje laboral global», Problemas del Desarrollo, vol. 46, núm. 183, 2015.
}

bre explotación. A su vez, el capital financiero se apropia de grandes excedentes acumulados por el valor social bajo la modalidad de intereses de deuda pública, privada y familiar, por lo que termina siendo uno de los grandes explotadores del sistema por vía indirecta.

A la gran diferenciación social emanada de las diversas formas de explotación directa e indirecta que recalan en una multiplicidad de segmentos laborales dispersos se suma la variedad de singularidades constitutivas de los sujetos acordes a la mixtura multiétnica (indígena, mestizo, anglosajón, negro, árabe), multilingüístico (lenguas occidentales y de los pueblos originarios), heterogeneidad sexual (heterosexual, homosexual). Lo anterior exhibe una compleja mixtura social que tendría que ser indagada a profundidad por la crítica de la economía política y los estudios críticos de la cultura.

En el presente, la masa desbordante del proletariado internacional se multiplica con la incorporación del exbloque soviético, China e India a la trama del capitalismo internacional, razón por la que las grandes corporaciones tienen a su disposición un vasto ejército laboral que sobresale por su desorganización, precarización y desvalorización. En los países sometidos a los programas neoliberales se han implementado severos programas de ajuste y reformas laborales en contra de los intereses sindicales, políticos y salariales de los trabajadores. Como parte de la normalidad neoliberal ahora emergen grupos de trabajadores completamente precarizados. ${ }^{36}$

Un dato sintomático de la expansión del proletariado, que a la par es una síntesis de la actual crisis civilizatoria, es la persistencia y el acrecentamiento de las migraciones dentro de los Estados nacionales y entre ellos por causas como el despojo, la violencia y la miseria. Se trata de una migración forzada del proletariado

\footnotetext{
${ }^{36}$ Guy Standing, El precariado. Una nueva clase social, Barcelona, Pasado \& Presente, 2011; Adrián Sotelo, El precariado: ¿nueva clase social?, México, Miguel Ángel Porrúa, 2015.
} 
internacional, que ya había sido explorada en el capitalismo industrial clásico de Inglaterra, ${ }^{37}$ pero que en este momento cobra auge en el capitalismo neoliberal. ${ }^{38} \mathrm{El}$ proletariado nómada es el signo más conspicuo de la crisis humanitaria que entraña la barbarie capitalista.

\section{Involución ortodoxa y horizonte libertario}

Ha sido un aspecto controversial la formación del proletariado como sujeto histórico que habrá de transformar el capitalismo para convertirlo en otra sociedad, socialista o comunista. El marxismo tradicional únicamente consideraba la existencia de un solo tipo de proletariado, el industrial, que era explotado en la línea de producción de la fábrica y producía plusvalor. Para ciertas visiones marxistas, el proletariado entraña un «orgullo de clase», un fuerte sentido de pertenencia, que se adhiere a la visión progresista sobre el desarrollo de las fuerza productivas. En el marxismo prevaleció un «orgullo proletario», pues se consideraba que dicha clase era la «elegida», la sepulturera del capitalismo. Esta clase producía la riqueza de la sociedad y mantenía a la burguesía. La presunción revolucionaria descansaba en la idea de que el proletariado consciente y organizado en un partido obrero sería dirigido por una vanguardia para derrocar el dominio del capital e instaurar un Estado obrero, la denominada dictadura del proletariado.

Esta intención revolucionaria ha estado anidada en los tratados y manifiestos políticos marxistas. Sin embargo, la experiencia catastrófica del socialismo realmente existente ${ }^{39} \mathrm{y}$ el triunfo del capitalismo neoliberal, dieron al traste con

\footnotetext{
${ }^{37}$ Karl Marx y Friedrich Engels, Imperio y Colonia. Escritos sobre Irlanda, México, Cuadernos de Pasado y Presente, 1979. ${ }^{38}$ Humberto Márquez Covarrubias, «Desarrollo y migración: una lectura desde la economía política crítica», Migración y Desarrollo, núm. 14, 2010.

${ }^{39}$ Adolfo Sánchez, El valor del socialismo, México, Ítaca, 2000.
}

cualquier intento para proclamar una nueva sociedad. Lo cual no quiere decir, sin embargo, que se hayan agotado las esperanzas populares del cambio social; es imprescindible que no se repitan los experimentos fracasados o contrahechos. El final del siglo XX y lo que va del presente ha sido escenario de grandes movilizaciones sociales en el planeta, sobre todo en los países subdesarrollados que buscan formas de autonomía, gobiernos populares y formas de socialidad alternativas.

Las luchas anticapitalistas son múltiples y variadas: movimientos, sindicatos y partidos. Unos buscan negociar mejores formas de inclusión dentro del sistema del gran dinero (salarios, horarios, condiciones de vida y trabajo), sin necesariamente pretender derrocar al sistema. Otros avizoran cambios sociales, proyectos utópicos, políticas de lo imposible. Entre las luchas antisistémicas se encuentran etapas intermedias, como la desmercantilización del trabajo, que incluye ideas como la redistribución social del ingreso, por ejemplo mediante las rentas (Estados progresistas, renta universal). Con todo, el ideal de emancipación humana sigue vigente y no puede ser ajeno a los trabajadores y las clases populares. 